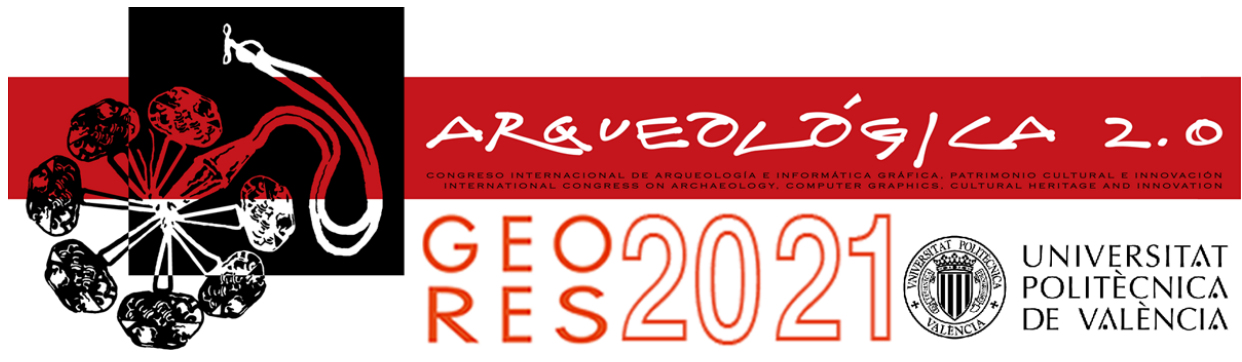

Proceedings of the joint international event $9^{\text {th }}$ ARQUEOLÓGICA

$2.0 \& 3^{\text {rd }}$ GEORES

Valencia (Spain).

26-28 April 2021

\title{
INFORMATIVE MODELS OF CULTURAL HERITAGE. THE “UNFINISHED” CHURCH OF BRENDOLA
}

\author{
Emanuela Sorbo*, Gianluca Spironelli \\ Dipartimento di Culture del Progetto, Università luav di Venezia, Palazzo Badoer, San Polo 2468, 30125 Venice, Italy. esorbo@iuav.it; \\ gspironelli@iuav.it
}

\begin{abstract}
:
The paper is an initial form of dissemination of the research activities carried out by the Università luav di Venezia working group which, on behalf of the Municipal administration of Brendola, seeks to delineate the application of a methodology for the study and analysis of the architectural and landscape heritage of significant cultural interest that is in a state of abandonment. The case study application is the church of San Michele Arcangelo in Brendola (Vicenza), known as the "Incompiuta" ("Unfinished"). The case study proposed is an interesting exemplar of ecclesiastical architecture, designed by engineer-architect Fausto Franco, in which its characteristics of being unfinished and in a state of ruin contribute to redefining the image of a work that fits in a historical context of architectural and technical experimentation, where the reference to historical architecture is mediated by contemporary forms and by the use of modern building materials, among which, the use of reinforced bricks is noteworthy. The research activity, which is taking place in the context of the COVID19 health emergency, aims at putting a series of strategies and operational practices based on the digitisation of data to the test, so as to allow increased interoperability and sharing through the building of an online open data repository addressed to the actors involved in the conservation process and to the community. In the processes of conservation and valorisation, in-depth knowledge and documentation of the materials and construction techniques involves multidisciplinary areas; effectively organising them in a system that regulates their collection, cataloguing, processing and archiving according to shared procedures, therefore becomes a fundamental prerequisite for the development of operational planning of the valorisation strategies. All the instruments that make it possible to collect data and reach a true knowledge of the object therefore become indispensable. From this point of view, the push towards the digitisation of the data that emerged during the pandemic phase plays a fundamental role in the range of application possibilities, from the survey to the mechanisms for the conservation and management of the cultural heritage.
\end{abstract}

Keywords: cultural heritage, unfinished architecture, interoperable digital documentation, HBIM database, experimental techniques, open knowledge

\section{Introduction}

The research activity is based on the following Memorandum of Understanding: "Il limite della Rovina. Procedure di conoscenza, analisi e valutazione dello stato conservativo della Chiesa 'Incompiuta' di Brendola" (The Limit of the Ruin. Procedures of knowledge, analysis and evaluation of the state of conservation of the 'Unfinished' Church of Brendola), stipulated between the Università luav di Venezia and the Municipality of Brendola through a funded research contract (file. no. 772020 prot. no. 1476 of $20 / 01 / 2020$ ). The memorandum of understanding promotes the identification of a study and analysis methodology for the architectural and landscape heritage of significant cultural interest found in a state of abandonment. The applied case study is the "Unfinished" Church of Brendola (Fig. 1). The aim of the research is to attain the creation of a system of knowledge concerning the building's state of conservation that allows the identification of conservation and valorisation strategies that can be shared with the bodies that are responsible for its protection as well as with the community of Brendola, acting as a possible reference for the development of operational guidelines in the best practice of the discipline of restoration.

\section{Case Study: The "Unfinished" Church of Brendola}

The earliest information found concerning the construction of the church dates back to 1904 . Historical events and construction report are collected in the writings of Don Francesco Cecchini (1937), Archpriest of Brendola, reference figure and promoter of the construction of the building. Dedicated to the city's patron saint, Michael the Archangel, the church rises isolated at the summit of Cerro Hill, in a barycentric position with respect to the nearby communities. As the Archipriest's

`Corresponding Author: Emanuela Sorbo, esorbo@iuav.it 
writings of 1915 clearly express, the temple "which responds to long-standing desires", was to have been built "out of concordant will and generosity", "in a place that is convenient to all", cementing "the scattered districts together in unity of faith and in piety of actions". The study of the project for the new church "which responds to the noblest ecclesiastical traditions" was entrusted on 10 January 1928 to the young engineer-architect Fausto Franco (1899-1968) who had recently obtained his second degree in architecture. Born in Vicenza on June 19,1899 , in 1922, at the age of twenty-two, he graduated in engineering at the University of Padova. In 1927, at the age of twenty-eight, he obtained his second degree in architecture at the Royal School of Architecture in Rome. (Ministero per i beni e le attività culturali et. al, 2011 and Gazzola, 1968).

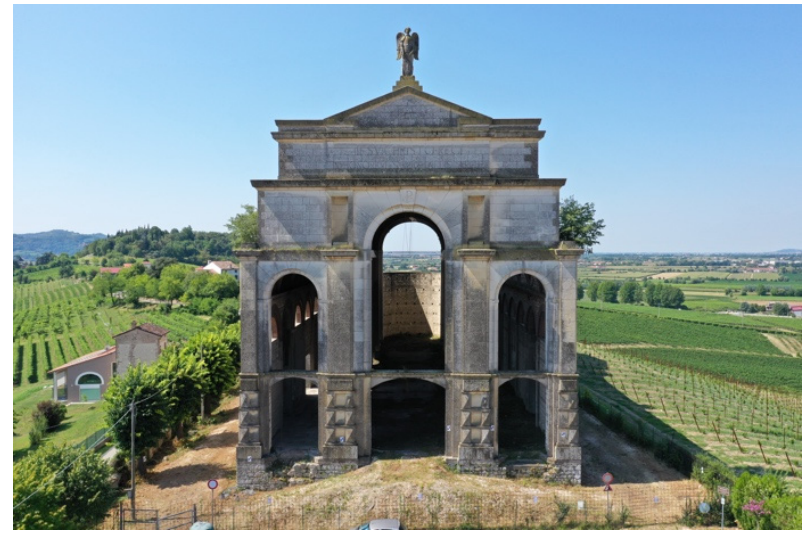

Figure 1: General view of the "Unfinished" church of Brendola.

A scholar of the ancient civilisations of the Middle East, starting from 1929, Franco was a student of the Archaeological School of Rome and Athens, taking part in numerous excavation and restoration campaigns with Professor Carlo Anti. In 1930 he was appointed Honorary Royal Inspector of the Monuments of Vicenza, where, in parallel with his archaeological activities, he began to study the work of Andrea Palladio. In 1933 he became part of the Antiquities and Fine Arts Department and was assigned to the Superintendence of Medieval and Modern Art of Milan, and soon after, to that of Venice; in 1939 he became Director of the Superintendence of Antiquities and Art of Venezia Giulia and of Friuli, where he remained until 1952. In parallel with his professional activity, in 1936 he obtained the qualification of professorship in History and Styles of Architecture (1936) and in Stylistic and Building Characteristics of Monuments (1937) at the University Institute of Architecture in Venice (1937-67). Observing the original project (Fig. 2), it is possible to see how the church is characterised by a typological layout that can be traced back to a Latin cross plan in Romanesque style, delineated by a rectangle measuring $53.5 \mathrm{~m} \times 22.5 \mathrm{~m}$, punctuated by three symmetrical barrelvaulted naves ending in semicircular apses. The central nave, which is twice as wide as the lateral ones, is defined by columns on pedestals ( 9 on each side) made of reinforced concrete and clad in pietra di Vicenza stone, connected by a series of round arches. The masonry structure is constituted of core-and-veneer masonry with concrete recesses and is punctuated by the presence of four semicircular chapels that flank the building's exterior and characterise its composition together with lunette openings located in the upper part of the facing walls.
In the Church of San Michele Arcangelo, Franco manages to combine the architectural language with an experimental use of mixed construction techniques, characterised by the juxtaposition of different materials and techniques; the use of reinforced brick elements in the roof structures is noteworthy.

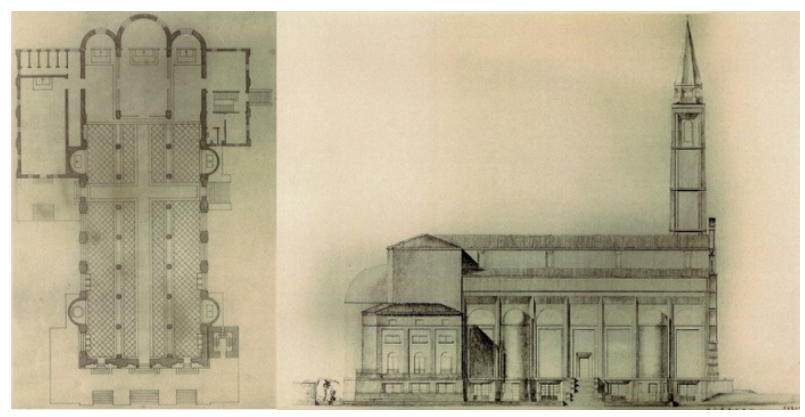

Figure 2: Original drawings made by Fausto Franco.

The inclusion of the project in the landscape was the object of evaluation, on 2nd October 1931, by the artistic commission composed of important figures in the national panorama of conservation such as Ferdinando Forlati (1882-1975 one of the protagonist of the post-war reconstruction of monuments after the First and Second World Wars) of the Royal Superintendence of Monuments of Venice, Luigi Ongaro, Vice President of the Provincial Monuments Commission and Director of the Civic Museum of Vicenza, and Giuseppe Stocchiero, Commissioner of Sacred Artworks for the diocese of Vicenza, all of whom were called to "consider the project and the orientation of the church in relation to the landscape requirements". The construction officially began on 3rd October 1931, with the blessing of the foundation stone by Bishop Ferdinando Rodolfi and continued as planned until 1934, a year that marked a turning point, characterised by the suspension of the construction site due to the Archpriest's replacement for reasons of health. On 20th March 1939 the Bishop authorised the resumption of the construction works at Cerro, but with limited resources, insufficient for the completion of the work. In 1940, in support of the continuation of the work, Fausto Franco intervened and, addressing the Bishop, pointed out the critical issues that the interruption of the construction works would have entailed, stressing how the failure to build the roof would have rendered futile the work completed up to that point. Notwithstanding the economic difficulties, in October 1940 , permission was granted for the roofing of the building, which was completed in 1941. The impossibility of receiving new funding and the death of Father Cecchini on 18th May 1949 brought the construction site to a standstill, leaving the sacristy area, a chapel and the bell tower unfinished. Following its abandonment, the church was purchased by the Municipal administration of Brendola in 1997, with the commitment of using the building for social or cultural purposes of public utility. Since 22nd June 2009, the church has been under the protection of Legislative Decree no. 42 of 2004, which defines it as "the only evidence of the activity of an architect with an original and eclectic personality, fully integrated into the Italian culture of the 1930s and, in particular, in the architectural debate that was emerging following the great archaeological campaigns in Africa and Asia". 


\section{Method}

The fields of investigation of the research activity have entailed a first phase of historical-critical investigation aimed at identifying the information useful for developing a critical knowledge of the cultural property, together with a campaign of inspections aimed at carrying out the geometric survey of the building and the analysis and cataloguing of the vulnerable elements and the mechanisms of deterioration. This first phase involving the gathering of information makes it possible to compare and interpret the data obtained and to reach different levels of knowledge, making it possible to delineate strategies for the valorisation of the cultural property through the use of digital technologies for data sharing and dissemination by building an online repository and an HBIM database. The collection of documents involves the gathering of elements belonging to different contexts; given the above, it has been decided to orient the structure of the database towards an architectural study aimed at identifying those documents that can retrace the construction phases of the building and that can bear witness to its architectural value. For each of the documents scanned and catalogued, wherever possible, optical character recognition has been performed in order to make the contents searchable by means of computer devices.

\subsection{Field acquisitions}

The data acquisition and processing campaign, led by the CIRCE photogrammetry laboratory of the Università luav di Venezia, was conducted with the use of different types of surveys related to specific theoretical and operational procedures. The necessary instrumental and methodological apparatus was evaluated, in relation to the complexity of the building and to the scale of representation required for the subsequent multidisciplinary analyses. The survey operations were carried out through the implementation of topographic, laser scanner and photogrammetric surveys (Castagnetti et. al. 2016), programmed according to an effective data acquisition campaign that made it possible to complete the acquisition operations in a single day. The first operation carried out concerned the design of the polygonal structure, leading to the definition of six cornerstones upon which to position the full station. The conformation of the church and the presence of natural obstacles made it impossible to make some of the points of the polygonal structure visible from several points of the station. In order to overcome the problem and to allow a good stiffening of the grid, it was decided to place some passage points on the building in positions visible from several station points. Once the structure of the grid was defined, the cornerstones were materialised in the field and 87 support points were marked with special paper targets (checkerboard) applied to the building. The support points positioned, together with architectural points identified on the building, facilitated the orientation of the photogrammetric survey and the various scans carried out by means of the laser scanner. The topographic observations of the detail points were collected by irradiation with a Leica TCR 1103 full station with $\mathrm{Hz}$ and $\mathrm{V}$ precision of $1 \mathrm{mgon}$ and $3 \mathrm{~mm} \pm 3 \mathrm{ppm}$ in distance measurement.

The photogrammetric survey was carried out using digital cameras and software based on Structure from Motion
(SFM) and Multi View 3D Reconstruction algorithms, using the commercial reference software: Agisoft Metashape Pro. The photogrammetric images were recorded using Nikon D800 type digital terrestrial cameras with a focal length of $20 \mathrm{~mm}$ and 36 megapixel full frame CMOS sensor, and aerial cameras using DJI Mavick 2 Pro type RPAS (Remotely Piloted Aircraft Systems) equipped with Hasselblad L1D-20c camera with $35 \mathrm{~mm}$ focal length equivalent to $28 \mathrm{~mm}$ and 1" 20 megapixel CMOS sensor, and DJI Phantom 4 Pro equipped with FC6310S camera with $35 \mathrm{~mm}$ focal length equivalent to $24 \mathrm{~mm}$ and 1" 20 megapixel CMOS sensor. The imaging positions were divided into two macrogroups, one dedicated to the survey of the internal façades and one dedicated to the external ones; each macro-group was then divided into sets with different imaging modes and distances: the farthest sets made it possible to identify an overall view, while those closer to the object made it possible to acquire data with a higher resolution for the detailed representation of the façades. Overall, the operations led to the recording of 1,533 images. As far as the laser scanner survey is concerned, the acquisition operations were carried out using two phase-measurement instruments, Faro Focus 3D S120 and Focus $S 150$, which are characterised by their high precision and the speed of their data acquisition (up to 976,000 points per second). The scans, 34 in all, have been acquired by positioning the instrument in such a way as to minimise the formation of shadow cones as much as possible and to ensure an adequate overlap with the previous scans. The individual scans were orientated in the local reference system thanks to the previously positioned targets. The distance between the instrument and the object of the survey was evaluated in order to guarantee a density of about one point every centimetre at a distance of 10 metres.

\subsection{Materials analyses}

The building of the church of San Michele Arcangelo is characterised by a strong presence of modern construction techniques juxtaposed with traditional techniques (Fig. 3). Among the historical documents related to the construction of the church, it is possible to find descriptions of the building materials used, including those of the stone elements, which can be traced back to the use of "pieta bianca di san Gottardo" (white San Gottardo stone), "pietra gialla dei Berici" (yellow Berici stone) and "Trachite Euganea".

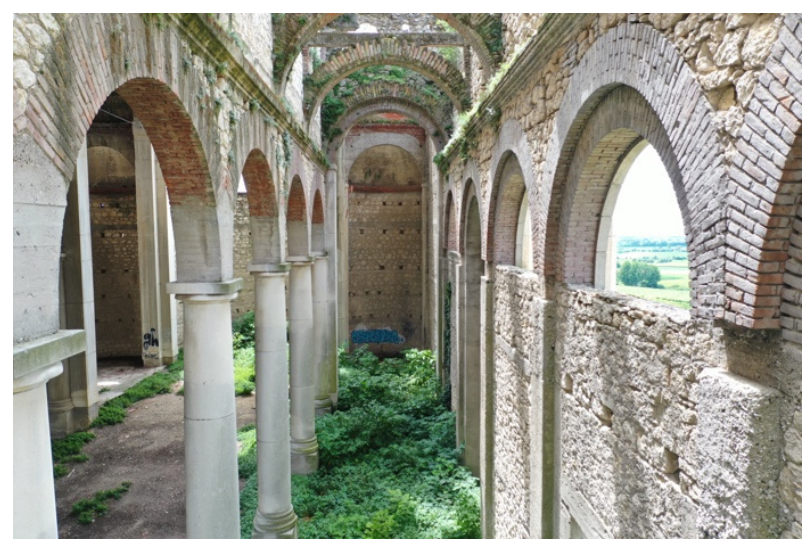

Figure 3: View of the interior spaces of the church after the abandonment. 
An element that opens an interesting field of investigation in the understanding of the vulnerabilities found in the masonry is represented not so much by the quality of the stones used, mainly due to the use of "pietra di Vicenza" (Vicenza stone), but rather by the quality of the mortars and the stone cladding. In this sense, the subsequent phases of characterisation of the masonry will be oriented where, through assays and laboratory analyses, the quality of the mortars and the relative critical points that may have influenced the behaviour of the masonry over time will be identified, also in relation to the presence of different construction techniques.

\section{Results obtained}

The use of laser scanner and photogrammetric survey methods has allowed a considerable reduction in acquisition times and has lessened the possibility of operator error. The laser scanner survey has been the most effective methodology for the survey of the architecture in its complexity, thanks to its high acquisition speed and the considerable amount of information it was able to collect. The photogrammetric survey, on the other hand, made it possible to integrate the portions of the building not directly accessible from the ground, such as the roof structures, and at the same time, made it possible to acquire data with a high photographic resolution useful for the detailed representation of the façades by means of orthophotos generated by the three-dimensional model obtained. The local reference system generated by the topographic survey made it possible to orient and join together, thanks to the topographic support points, the point cloud obtained by joining the different laser scans with the point clouds obtained by means of photogrammetry.

From the point of view of the precision obtained, the processing of the laser scans led to a difference of about $0.5 \mathrm{~cm}$ while, as far as the point cloud obtained by photogrammetry is concerned, a precision in the region of one centimetre was reached, perfectly in line with the expected scale of representation. An experimental element introduced in the processing of the large number of images is the use of a cloud processing service. This has made it possible to drastically reduce processing times, making post-processing and rendering operations possible on a normal computer. The processing of the point cloud (Fig. 4) will make it possible to evaluate the actual geometry of the components of the structure, identifying possible deviations from the plane of the facing walls or of subsidence, described by a continuity of points and not by a discretisation operation carried out by the surveyor. The point clouds obtained, together with the analysis carried out on the building, established the basis (Bruno et. al. 2013) for the development of the informative model of the church that collects its identity data and its vulnerabilities, configuring itself as a useful project tool for the delineation of hypothetical guidelines for a conservative design project.

\subsection{HBIM Database}

Through the critical analysis of sources and data collected, the in-depth study of cultural heritage allows looking at these cultural assets as fragments of stratified memory (Augé, 2004) that meet the criterion of uniqueness. Associate the construction of BIM models to the cultural heritage means to weave different knowledge composed by material and immaterial values that sometimes hardly fall within the concept of standardization and parameterization that is usually associated with the construction of informative models for architecture (Attenni, 2019). In the construction of informative models for the cultural heritage, every object, even if defined by characteristics common to other elements, is configured as a unicum defined by a rigorous semantics.

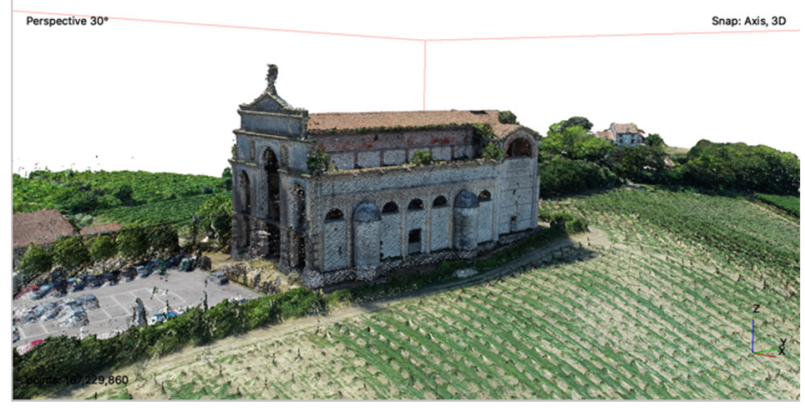

Figure 4: Final point cloud.

The construction of HBIM models, as in the case of the unfinished church of Brendola (Fig. 5), deals with managing a large amount of data. The collection of this data presupposes a philological reconstruction of the information that allows reconstructing of the archival and bibliographic sources used in the association of the data to the geometric model.

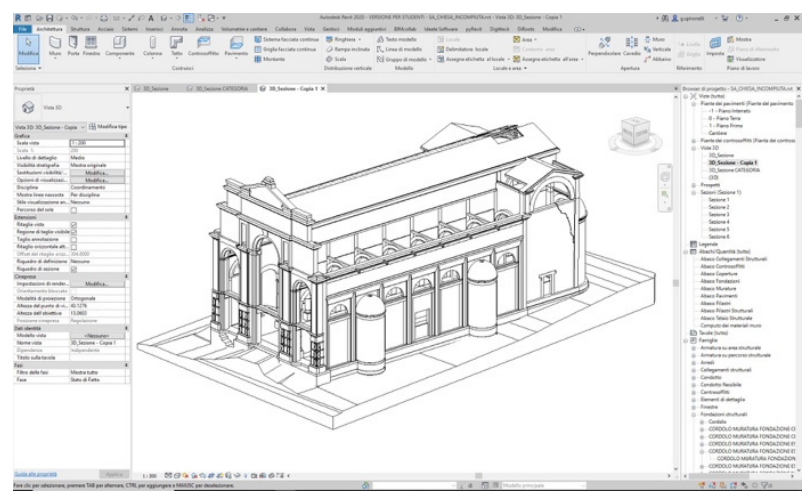

Figure 5: View of the HBIM model of the "Unfinished" church of Brendola.

This method of comparative study, which embraces technique and cultural humanism, was the basis of the decision to structure the information in databases (Fig. 6) that would act as a system for an archival and constructive investigation (Acierno, Cursi, Simeone, \& Fiorani, 2017) of the architectural elements in parallel with the assessment of the state of conservation and the design choices. This assumption was the base to develop an HBIM model connected to a repository that can be consulted and implemented (even by non-specialized personnel). The analyses carried out, within the archival documents, are associated with each architectural element. This tool wants to be the key to a multi-level interaction of knowledge and data sharing structures over time, being a vehicle for historical investigation and design.

The digital model's construction took place within the Autodesk Revit 2020 work environment, one of the sector's leading reference software. The choice of 
constructing the church's HBIM model within a commercial software is dictated by the fact that (currently) there are no valid open-source alternatives that allow managing an informative model with the same effectiveness.

While on one hand the modelling of architectural elements and the association of information content passes through the use of commercial software, on the other hand, the setting given to the model guarantees a high possibility of access and modification (Diara, \& Rinaudo 2018) thanks to the IFC (Industry Foundation Classes) scheme.

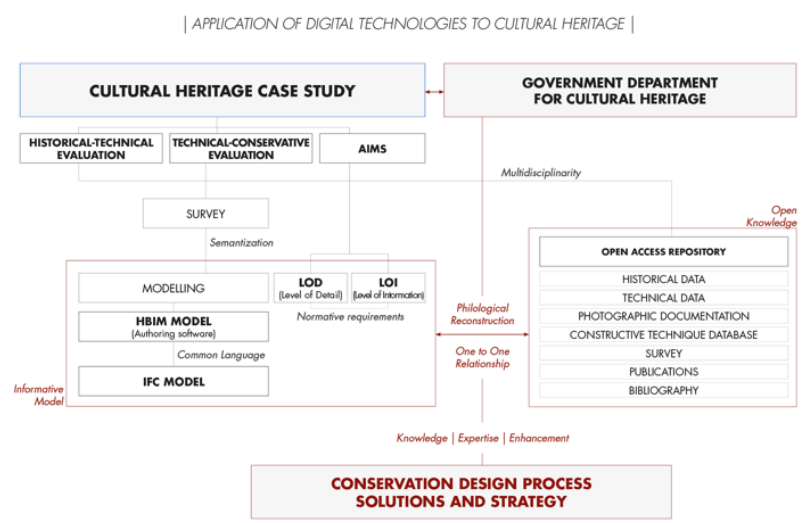

Figure 6: Schema of the workflow of the research activities.

The research activity's final objective is to achieve the definition of a system of knowledge of the church. A digital model of the architecture developed according to the IFC scheme allows obtaining a one-to-one correspondence between the model and the repository information. The diriment element in the system's construction is represented by choice to collect within the digital model the information collected in the phases of historical-critical investigation and knowledge of architecture through synthetic attributes (Fig. 7). The use of synthetics attribute allows to directly interrogate the model by using query (Fig. 8). Additional value is given by using dynamic links to specific directories of the repository where the data are collected.

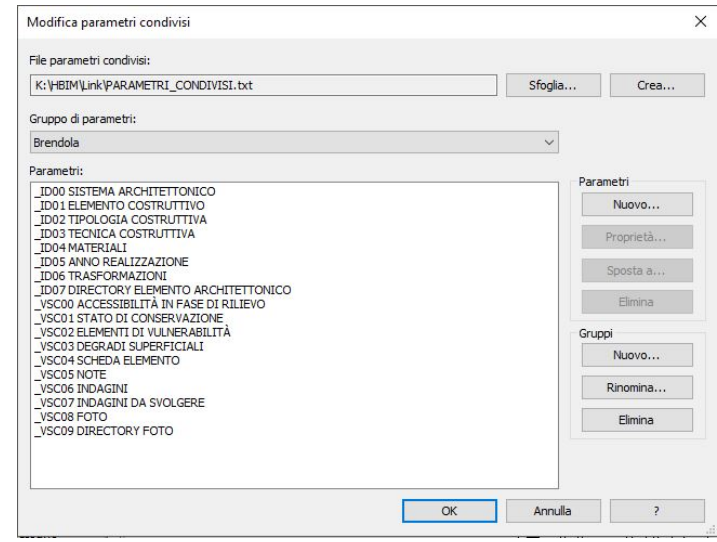

Figure 7: List of attributes coded according to shared parameters used to describe the identity data of the construction elements and their evaluation of the state of conservation. In order of appearance: Architectural System, Building Element, Construction Typology, Materials, Year of Construction, Transformations, Architectural Element Directory, Survey Accessibility, State of Conservation, Vulnerability, Decay Process, Element Data Sheet, Notes, Investigations, Investigations to be Carried Out, Photos, Photos Directory.
In this sense, the model becomes a tool with which it is possible to relate different access levels to the architecture's knowledge (Nazarena \& Roncella 2019 and Quattrini, Pierdicca, \& Morbidoni, 2017).

The construction of digital models for cultural heritage passes through the need to represent complex geometry, often difficult to reproduce except with specific software. It is well known how the main BIM applications' essential modelling tools can represent a limit in describing complex shapes (Murphy, McGovern, \& Pavia, 2009). Its definition passes through simplifications that do not respect the elements' real morphology, often defined by construction irregularities and the patina of time. During the semantization phase of the field's acquired data, the characterisation of the constructive elements (Brusaporci, Maiezza, \& Tata, 2018) passes through the notion of LOD (Level of Detail) and LOI (Level of Information), themes treated by two milestones normative requirements, the American Institute of Architects (AIA) with the AIA G202 Protocol, and the Italian UNI 11337

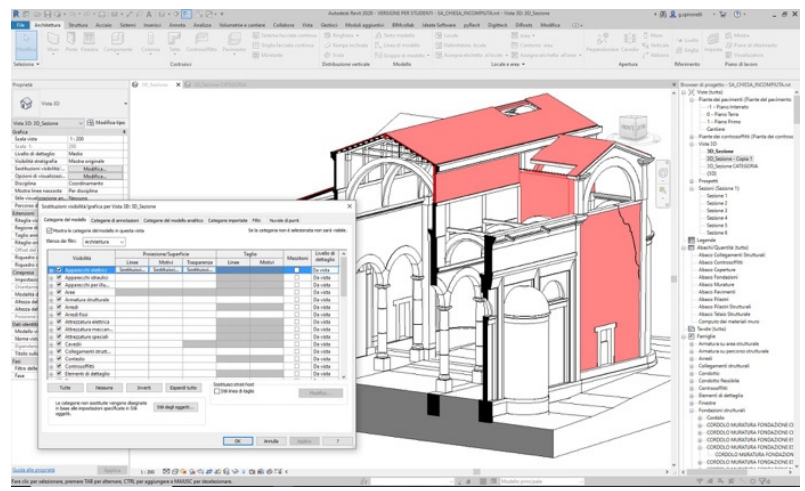

Figure 8: Example of a query created within the Autodesk Revit 2020 authoring software. Through a filter applied to the view, it is possible to highlight all the constructive elements with a severe state of conservation.

The church's informative model's construction was conceived following the criteria used during the construction site phases (Brumana, Georgopoulos, Oreni, Raimondi, \& Bregianni, 2013). From this point of view, the church's digital model's construction was carried out using the native instruments available on the software, basing the modelling of complex geometry on the "model in place" asset.

The use of local models is a powerful modelling tool that, in most cases, avoid the use of external resources (Tommasi, Achille, \& Fassi 2016) and give access to a series of advanced modelling tools that allow reproducing complex architectural elements faithfully. Compared to the point cloud obtained instrumentally, the modelling operations' accuracy led to an average deviation of the model of about two centimetres.

The association of information contents within geometric models referred to cultural heritage open up a wide field of investigation into the methods and shared procedures (Del Giudice \& Osello 2013) in which the data have to be associated with the digital model. Although in the field of cultural heritage an open-bim standard for collecting the information has not yet been delineated by the non-profit organisation "buildingSMART", the research group's goal is to identify the possible features that, through the IFC scheme may define their characterisation and their 
conservation status. (Fig. 9). As reported in Baldwin (2019), IFC is not an exchange format but a hierarchical structure that provide the organisation and the transportation of digital data. In this schema each object is defined and described by relationship and property.

The operation resulted in the search for the identity information necessary to describe the architectural element observed and its conservation status encoding them in a series of synthetic attributes associated with the model elements by introducing a series of "shared parameters" linked with the different categories of the model. This operation made it possible to combine the attributes, commonly available in the software, with specific features that refer to the heritage data.

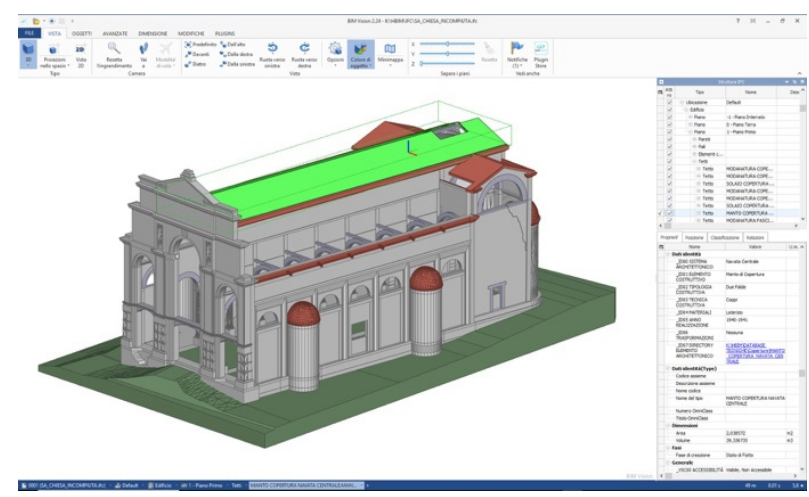

Figure 9: Example of the visualization of the data contained in the HBIM model within the open-source BIM Vision application.

The use of "shared parameters" has made it possible to collect information within specific schedules referring to the different architectural systems, ensuring high interoperability and allowing for the possibility of one-toone modification between model and schedule. The interoperability is ensured by the open-source plugin SheetLink (2020) developed by "DiRoots" company, which enables the export of the information in the form of spreadsheets with the possibility of being modified, also by non-specialized persons, in any application that supports its editing. This operation will allow a progressive advancement of knowledge linked to the asset and the possibility of managing the aspects related to conservation.

\section{Conclusions}

The studies carried out so far on the church show how the acquisition and processing of three-dimensional models supported by high-resolution digital images, together with the use of CAD tools and HBIM methodology, contribute to providing valuable support to the preliminary knowledge of the building. This instrumental premise interfaces with the theoretical and methodological assumption of recovering and enhancing the intangible value of the abandonment and the state of ruin of the Church, as well as its being an unfinished fragment (Augé, \& Meneguzzo, 2013), crossing the balance of the relationship between material traces and collective memory in an attempt to grasp the limits and opportunities of transmission.

\section{Acknowledgements}

We would like to thank: the Municipal Administration of Brendola for the great helpfulness it has shown us; the CIRCE Photogrammetry Laboratory for its willingness to carry out the activities and for having made the laboratory equipment available to us; the Superintendence of Archaeology, Fine Arts and Landscape for the provinces of Verona, Rovigo and Vicenza in the person of Silvia Dandria for the continuous support in the acquisition of data and the evaluation of conservation strategies; and Professors Mauro Marzo, Ettore Muneratti and Claudio Bertocco for their advice. Finally, we would like to thank Architect Gaetano Cecchini and Martino Albiero, for providing us with some of the historical data on the Church.

\section{References}

Acierno, M., Cursi, S., Simeone, D., \& Fiorani, D. (2017). Architectural heritage knowledge modelling: An ontology-based framework for conservation process. Journal of Cultural Heritage, 24, 124-133. https://doi.org/10.1016/j.culher.2016.09.010

AIA. (2013). AIA Contract Documents. G202-2013 Project BIM Protocol (aiacontracts.org). Retrieved March 15, 2021, from https://www.aiacontracts.org/contract-documents/19016-project-bim-protocol

Attenni, M. (2019). Informative Models for Architectural Heritage. Heritage, 3, 2067-2089. https://doi.org/10.3390/heritage2030125

Augé, M. (2004). Rovine e macerie. Il senso del tempo. (Ruins and rubble. The sense of time) Bollati Boringhieri.

Augé, M., \& Meneguzzo, M. (2013). Non-finito, infinito. Paolo Delle Monache film di Benoit Felici. (Unfinished, infinite. Paolo Delle Monache film by Benoit Felici). Mondadori Electa.

Baldwin, M. (2019). The BIM-Manager: A Practical Guide for BIM Project Management. Beuth Innovation.

Brumana, R., Georgopoulos, A., Oreni, D., Raimondi, A., \& Bregianni, A. (2013). HBIM for Documentation, Dissemination and Management of Built Heritage. The Case Study of St. Maria in Scaria d'Intelvi. In International Journal of Heritage in the Digital Era, 2(3), 433-451. https://doi.org/10.1260/2047-4970.2.3.433

Bruno, N., \& Roncella, R. (2018). A restoration oriented HBIM system for cultural heritage documentation: the case study of parma cathedral. Int. Arch. Photogramm. Remote Sens. Spatial Inf. Sci., XLII-2, 171-178. https://doi.org/10.5194/isprs-archives-XLII-2-171-2018

Brusaporci, S., Maiezza, P., \& Tata, A. (2018). A framework for architectural heritage hbim semantization and development. In ISPRS - International Archives of the Photogrammetry, Remote Sensing and Spatial Information Sciences, XLII- 
2, 179-184. https://doi.org/10.5194/isprs-archives-XLII-2-179-2018

buildingSMART. (2021). buildingSMART - The Home of BIM. Retrieved March 15, 2021, from https://www.buildingsmart.org

Castagnetti, C., Dubbini, M., Ricci, P.C., Rivola, R., Giannini, M., \& Capra, A., (2016), Critical issues and key points from the survey to the creation of the historical building information model: The case of Santo Stefano Basilica. International Archives of the Photogrammetry, Remote Sensing and Spatial Information Sciences, XLII-5/W1, 467474. https://doi.org/10.5194/isprs-archives-XLII-5-W1-467-2017

Cecchin, F. (1937). Il giubileo arcipretale nella parrocchia di San Michele arcangelo in Brendola: 19 Maggio 1912 - 19 Maggio 1937 (The archpriest's jubilee in the parish of San Michele Arcangelo in Brendola: 19th May 1912 - 19 th May 1937). Tipografia commerciale.

Del Giudice, M. \& Osello, A. (2013), BIM FOR CULTURAL HERITAGE. Int. Arch. Photogramm. Remote Sens. Spatial Inf. Sci., XL-5/W2, 225-229. https://doi.org/10.5194/isprsarchives-XL-5-W2-225-2013

Diara, F., \& Rinaudo, F., (2018) Open source hbim for cultural heritage: a project proposal, in The International Archives of the Photogrammetry. International Archives of the Photogrammetry, Remote Sensing and Spatial Information Sciences, XLII-2, 303-309. https://doi.org/10.5194/isprs-archives-XLII-2-303-2018

Gazzola, P. (1968). In Memoriam. Per Fausto Franco: 1899-1968. Arte Veneta, XXII, 217-218.

Murphy, M., McGovern, E., \& Pavia, S. (2009). Historic building information modelling (HBIM). Structural Survey, 27(4), 311-327. https://doi.org/10.1108/02630800910985108

Nazarena, B., \& Roncella, R. (2019), HBIM for Conservation: A New Proposal for Information Modeling. Remote Sens., 11, 1751. https://doi.org/10.3390/rs11151751

Quattrini, R., Pierdicca, R.;ç, \& Morbidoni, C. (2017). Knowledge-based data enrichment for HBIM: Exploring high-quality models using the semantic-web. Journal of Cultural Heritage, 28, 129-139. https://doi.org/10.1016/j.culher.2017.05.004

Sheetlink (1.2.2). (2020). [Free Revit plugin that allows you to sync the model data back and forth between Revit and Excel]. DiRoots. Retrieved March 15, 2021, from https://diroots.com/plugins/sheetlink-revit-to-excel

Tommasi, C., Achille, C., \& Fassi, F., (2016) From point cloud to BIM: A modelling challenge in the Cultural Heritage field. In ISPRS - International Archives of the Photogrammetry, Remote Sensing and Spatial Information Sciences, XLIB5, 429-436. https://doi.org/10.5194/isprs-archives-XLI-B5-429-2016

UNI - Ente Italiano di Normazione. (2017). UNI 11337-4:2017. Https://Www.Uni.Com. Retrieved March 15, 2021, from http://store.uni.com/catalogo/index.php/uni-11337-4-2017.html 